\title{
The Problem-Based Learning Gaze: A Foucaultian Perspective
}

\author{
Dr Salochana Lorraine Hassan
}

Cape Peninsula University of Technology

E-mail: hassanl@cput.ac.za

\section{Doi:10.5901/mjss.2014.v5n10p443}

\begin{abstract}
PBL is often valorized but has not, hitherto, been examined in terms of the way in which power manifests through group dynamics and how this might influence learning. In this paper, Foucault's theory of power, as in "Discipline and Punish: The Birth of the Prison", is used as a conceptual framework for gaining a deeper understanding of PBL group work. According to Foucault, it is not a person who has a hold on power, but rather visibility that assures the hold of power. Specifically, this paper examines the PBL "gaze" and its hold on students. During PBL tutorials, the tutor (and peers) was able to closely observe and continuously judge the performance of students during both participation and non-participation. Tutors and peers alike were able to judge the functioning of the group at a glance. During PBL tutorials it was this surveillance which kept students under subjection. They may never have known when they were being watched and their performance monitored and, they therefore, held themselves in subjection, controlling their behavior, speech and interaction with one other. Students could have experienced this type of surveillance and self-surveillance as threatening and oppressive, and it could have constrained their learning. This article provides recommendations for PBL tutors regarding the cognizance of the manifestation of power when it comes to the management of group dynamics so that tutorials can be a positive place for all group members. Although this study looked at group dynamics within the context of PBL, the argument regarding tutorials not being power-free zones could be applicable to other forms of collaborative learning.
\end{abstract}

Keywords: Collaborative learning; critical theory; evaluation; medical education; problem-based learning

\section{Introduction}

One of the major hallmarks of Problem-based Learning (PBL) is collaborative learning within small group settings (Van Berkel and Dolmans, 2006). Group work is generally perceived in a positive light and is often applauded (Van Berkel and Dolmans, 2006) in addition to being viewed as a way to promote creativity (Paulus 2003, Grossen 2008). Studies around group work are concerned mainly with the cognitive activities that constitute PBL pedagogy (De Grave, Boshuizen and Schmidt, 1996) largely because of the push for PBL to be seen from a constructivist perspective.

Constructivism underpins PBL (Ertmer and Newby 1993) and has a profound influence on the methods of teaching and learning. The design of this environment is meant to stimulate and engage the student (Savery and Duffy, 1996). It is advocated that student learning happens most effectively in an environment that is conducive to the creation of one's own meaning and through tutorials (Van Berkel and Dolmans, 2006).

The acknowledgement of the more knowledgeable other in promoting learning among students has led to the notion of scaffolding which occupies the constructivist agenda. In this regard, the role of the tutor in scaffolding learning among students, and the management of group dynamics has been reported by Hmelo-Silver (2004) and Papinczak, Tunny and Young (2009). Scaffolding in PBL affects the way in which tutors apply their discipline knowledge. In a previous publication this researcher (Hassan, 2010) explains that PBL tutors do not give up their discipline knowledge, but instead use it in a different manner during the facilitation of PBL group discussions in order to help students construct meaning.

In a constructivist environment, such as that offered by PBL, students are given the freedom to engage in selfdirected learning and create their own meaning (which is the basis of constructivism).

The social environment created by small-group tutorials has been applauded as a contributor to the success of "active-learning curricula" and "promoting persistence" among students (Schmidt, Cohen-Schotanus and Arends 2009, p. 216).

During PBL tutorials, students work in small collaborative groups and the PBL tutor acts as a facilitator of learning. The tutorial process starts when students are presented with a problem scenario and are expected to generate hypotheses and derive learning issues in addition to being active participants in accordance with structured group 
dynamics. They are required to demonstrate self-directed learning skills especially when they present information that they would have researched by themselves (Barrows, 1986; Hmelo-Silver, 2004).

In this article, Foucault's theory of power is applied within the context of PBL tutorials. For Foucault (1995), it is not a person who has a hold on power; but visibility (through Panoptic principles) that assures the hold of power. This type of surveillance is also referred to as the 'gaze' and within the context of PBL, specifically, it is referred to in this article as the 'PBL gaze'. The argument in this article centres around the way in which the PBL gaze holds students in subjection, as well as its power to compromise learning.

This article argues from the perspective of Foucault's theories that the structured nature of group work in PBL promotes the manifestation of power, and dominance by some members to flourish, creating an oppressive, threatening space where members are under constant surveillance (see Hassan, 2013).

However, just because group work in a PBL environment appears social and democratic, since students are selfdirecting, does not necessarily mean that they are in a power-free zone. In this regard Tan (p. 62) warns that: 'The naïve assumption that students are naturally able to exercise responsibility and control for their learning in Problem-based Learning contexts should be avoided.' He goes on to explain that: 'Student empowerment can only be realized if the ways power is exercised over students in Problem-based Learning practices are first understood' (Tan p. 62).

Although not plentiful, there is some literature on power within PBL environments. These studies mostly focus on the problem cases used in PBL, with scholars in the field arguing that the formulation and analysis of the problem is potentially a mechanism for control over what and how students learn (Drinian, 1997; Fenwick and Parsons, 1997; Tan). Other researchers (Ball, 1990; Reynolds and Trehan, 2000) direct their attention to assessment as sites of control. They warn of the danger of using self-assessment (for example) as an instrument to get students to sacrifice themselves to surveillance, subjecting themselves and becoming their own policemen.

These studies, however, do not focus on group work in PBL and as a result group dynamics as a manifestation of power has been neglected. A review of the literature shows that group work is not often examined in terms of the way in which power is manifested through group dynamics nor on how this might influence learning.

From this researcher's experience with PBL, these processes have the potential to create opportunities for hierarchies of power to exist among group members. Students are under constant surveillance by their peers and the PBL facilitator, and are expected to perform according to the strict rules and procedures dictated by PBL methodologies.

In order to address this research problem, the following research question was posed: How does the gaze affect the dynamics of PBL group work? In addressing this question, Foucault's theory of power is used as a conceptual framework for the study.

\section{Theoretical Framework}

In this paper, Foucault's theory of power, as in 'Discipline and Punish: The Birth of the Prison' (see Foucault, 1995) is applied as a conceptual framework for a deeper understanding of small group collaboration during PBL tutorials.

\subsection{The Panopticon, surveillance and self-surveillance}

Foucault uses the Panopticon architectural design as a metaphor for the pervasive inclination of society to observe. Designed by Jeremy Bentham, the Panopticon is a type of institutional building which is comprised of a central tower from which it is possible to see every cell which is occupied by a prisoner. The design allows a watchman to observe (-opticon) all (pan-) inmates of an institution without them being able to tell whether or not they are being watched.

Foucault (1995) argues that power (in Panopticism) should be visible and unverifiable. The prisoner must be able to see the location from which he is being observed (visible power) and may never know whether he is being watched at any given moment, but he must be aware that he could always be under surveillance (unverifiable power). Foucault (1995, p. 187) explicates that: 'It is the fact of being constantly seen, of being able always to be seen, that maintains the disciplined individual in his subjection.' Foucault (1995) further explains that the panoptic schema can be applied when dealing with a multiplicity of individuals on whom a task or particular behavior is imposed.

Interpreting Foucault's work, Brookfield (2005) explains that sovereign power from a discernible authority has been replaced by disciplinary power which is power exercised by people on themselves in specific areas of their daily practices. Brookfield (2005) argues that it is easier for educators to focus on sovereign power (such as the authoritative teacher) than it is for them to focus on their collusion in an exercise of disciplinary power and surveillance. 


\title{
2.1.1 Surveillance as a pedagogical tool
}

Foucault (1995, p. 203) indicates that the Panopticon is a type of laboratory where experiments could be conducted to change behavior, train individuals or try out pedagogical experiments. Surveillance, therefore, has a training and development function. In this regard, Brookfield (2005) acknowledges Foucault's work as being important in helping to recognize and understand the presence and effect of power in daily educational practice, particularly power that masquerades as beneficial power that is used to support learners in realizing their full potential.

Within a PBL environment surveillance is maximized though extensive and close interaction between PBL tutors and students. A structured PBL methodology has to be adhered to (particularly in medical education) during the problemsolving process and acquisition of knowledge (see Baker, 2000; Barrows, 1986; Collier, 2000; Walton and Matthews, 1989) and therefore, intensified surveillance becomes pivotal to the success of the PBL process.

\subsubsection{The panoptic arrangement in PBL tutorials}

Brookfield (2005, p. 131) refers to the circle which is used to equalize power relations in adult educational practice: 'The circle is sacred and reified in adult education as to be an unchallengeable sign of practitioners' democratic purity and learner centredness.' Brookfield maintains that:

\begin{abstract}
'Those adult educators with humanistic, progressive or radical sympathies take pride in their commitment to letting adult learners take control of their learning. They encourage adults to define their own curriculum, run their own classes and evaluate their own progress. A belief in the possibility that adults can be responsible for their personal and political selfactualization seems inherently liberatory. Foucault would have us think otherwise. To him power relations are manifest in all educational interactions, even those that seem the freest and most unconstrained.' (Brookfield 2005, p.130).
\end{abstract}

Foucault's argument can help us understand discussion groups as representing a laboratory of power: 'a complex mix of power laden practices'. For example, participants in discussion groups are subjected to a particular 'form of surveillance while superficially inhabiting a liberating space.' Brookfield (2005, p. 122).

When the panoptic arrangement is extrapolated to group work during PBL tutorials, Panopticon principles could apply. The PBL students will be in the presence of the PBL tutor who will observe them, but they will never know whether and when they are being watched. Power, therefore, becomes visible but unverifiable. The PBL tutor (and peers) is able to closely observe and be able to continuously judge the performance of students during participation and nonparticipation, and impose upon them the strict, structured methodological demands of PBL.

As a result, members of the group may become acutely aware that they are under surveillance. Students would hold themselves in subjection, controlling their behavior, speech and interaction with each other. Foucault (1995) maintains that the ultimate goal is for those being watched to be caught up in a power struggle of which they are the bearers. Thus, surveillance and self-surveillance in PBL could be experienced as threatening and oppressive and might actually constrain learning.

\section{Research Design}

In order to examine the manifestation of power through surveillance (or gaze) within the context of PBL group work, a mixed method approach was adopted in this research. This method involved quantitative studies (self-administered questionnaires) as well as qualitative studies (reflective journal entries and observational notes of PBL group work).

This study drew upon data obtained in a cross-continental higher education context encompassing South Africa and the UK. The data was collected during the period that this researcher was employed at the universities concerned (as a PBL tutor in the UK and South Africa, and as co-ordinator of the quality assurance of PBL in the UK).

\subsection{Context of the study}

In South Africa, the study was conducted within a medical faculty at a university in the Eastern Cape. In the UK, the study was conducted at a medical university in London. The UK students included in the study were at second year level and were part of a Graduate Entry Programme. 


\subsection{Sampling techniques}

Purposive and convenience sampling was applied and the target group was selected based on their involvement in PBL. They had to have been active participants of the PBL process and involved in small group discussions. The two South African target groups were comprised of the second year students of the MBChB programme during the first two years during the transition to PBL (Hassan, 1996). Thirty seven students in the first group and 44 students in the second group were involved in the study. The UK cohort comprised of 18 second year students in the MBBS programme, and was made up of three groups of six students.

\subsection{Quantitative study}

Self-administered questionnaires containing 30 structured items and one unstructured item, were used in the study. A Likert scale was adopted in designing the structured items and respondents were asked to agree or disagree along a four-point continuum: strongly agree (SA); agree (A); disagree (D) and strongly disagree (SD). The response rate for the first year cohort was $86 \%$ (or 32 respondents) and the response rate for the second year cohort was $77 \%$ (or 34 respondents).

The responses to the structured items were analyzed using descriptive statistics, such as the calculation of mean scores. In order to simplify the data analysis, the scores for the strongly agree and agree categories were combined and reported as agree while the scores for the strongly disagree and disagree categories were combined and reported as disagree. Unstructured items were analyzed using qualitative data techniques such as coding, categorization and the identification of themes.

\subsection{Qualitative study}

Reflective journal entries, document analysis and observational notes were employed in the collection of qualitative data in the UK and in South Africa. Data was analyzed using coding, categorization and the identification of themes. In order to keep the data uncomplicated and to help answer the research question only the codes and categories relevant to the themes of power, surveillance and self-surveillance were used.

\subsection{Results and discussion}

It is well known that in the traditional roles of teacher and student, power is exerted in a more overt manner where the teacher is the authority and poses as the sole bearer of the knowledge to be transmitted to the student. In a constructivist environment like PBL, the teacher assumes a new role; that of facilitator. They scaffold students' learning through modeling, coaching and ultimately fading some of their support (Hmelo-Silver, 2004; Hmelo-Silver and Barrows, 2006). This, however, should not be interpreted as the relinquishing of power by tutors. The findings of this study show that PBL tutors do not necessarily give up their power, but use it in a more subtle, insidious way through surveillance and ultimately self-surveillance. Arguably, students are under more control in a constructivist environment than the literature would have us believe.

\subsection{Perceptions regarding PBL tutorials.}

Students' experience of PBL tutorials in this study was positive as indicated by the empirical evidence reflected in table 1.

Table 1. Student's perceptions of PBL tutorials at a South African University (Hassan, 1996).

\begin{tabular}{|l|c|c|c|}
\hline \multicolumn{1}{|c|}{ Variable } & $\begin{array}{c}\text { Mean score } \\
\text { (first group) }\end{array}$ & $\begin{array}{c}\text { Mean score } \\
\text { (second group) }\end{array}$ & Perception \\
\hline Learning in groups is an effective way to gain knowledge. & 3,187 & 3,1818 & Agree \\
\hline $\begin{array}{l}\text { I am able to interact well on an interpersonal level with members in my } \\
\text { group. }\end{array}$ & 3,000 & 3,147 & Agree \\
\hline Tutors are good facilitators of group discussions. & 3,000 & 2,941 & Agree \\
\hline I look forward to attending tutorials. & 3,100 & 3,060 & Agree \\
\hline
\end{tabular}


Gramsci (see Brookfield, 2005) argues, however, that hegemony works when being oppressed is seen as a desired state to be in. Those being oppressed do not know that they are being oppressed and would have learnt to enjoy what they were experiencing. In reference to Gramsci's notion of hegemony, Brookfield (2005, p. 98) goes on to explain that it is about oppression through consent; people are not forced, against their will, to assimilate the dominant ideology, they do this willingly. Those being exploited will work to ensure their continued oppression, while taking pride in doing so.

Students' positive perceptions of group work (see table 1) could not be relied upon to answer the research question when Gramsci's notion of hegemony was applied. They might not have been aware that they were being oppressed. As far as they were concerned, PBL was a positive environment. Hence, they were not forced to accept the ideologies of PBL; they did this willingly. Underpinning these findings were power dynamics which were identified by other methods such as observational studies and reflective journal entries.

\section{The Role of Surveillance during PBL Tutorials}

Within the context of group work during PBL tutorials, the tutor (and peers) were able to closely observe, and continuously judge, the performance of students during participation and non-participation, and could impose upon them the strict, structured methodological demands of PBL. The PBL tutors and peers were easily able to judge how the group was functioning. Members of the group experienced a heightened sense of being under surveillance and were constantly aware that a lack of participation or weak contribution would be detected by other group members. Surveillance in PBL group work kept students under subjection.

The PBL tutor did not have to be a powerful person or even a content expert. In fact, there is evidence in the literature (De Grave, Dolmans and van der Vleuten, 1999) which suggests that tutors with less content expertise make better facilitators than content experts. What was needed was the presence of the tutor as an observer, watching and monitoring the PBL process. The PBL tutor did not even have to say anything; the students already knew that the PBL tutor was being vigilant for a particular pattern of behaviour.

In a PBL environment, non-participation by students blocked the gaze. When students were contributing and participating in group discussions, it was easier to watch and assess their performance. For this reason it became important for PBL tutors to ensure that students were actively engaged in discussions. Those who faltered were reprimanded through negative feedback from the PBL tutor and peers. From this researcher's experience, it was during training that the PBL tutors were encouraged to make a concerted effort to draw students into the discussion, ensuring active participation. Any attempts at avoidance of the gaze were met with even greater surveillance and monitoring. Hmelo-Silver (2006, p. 24) notes that: 'the facilitator must continuously monitor the discussion, selecting and implementing appropriate strategies as needed'.

This illustrates the power of surveillance, carrying with it its oppressive tendencies. This is acknowledged in the literature by Brookfield (2005) who proclaims that in a circle or group work there is pressure to participate and perform which can be experienced as humiliating, painful and oppressive. A journal entry made by this researcher regarding a PBL tutorial in the UK is shown below, as evidence of how painful the PBL experience can be for some students.

'Today the students appeared jovial and laughed a lot. I thought they were enjoying themselves and were seeing PBL as a pleasant experience so, I said: "I see you are having fun". They responded that it was nervous laughter. I wondered to what extent I, as a PBL tutor in the execution of my duties, was contributing to that nervousness.'

\subsection{The power of self-surveillance in PBL groups}

Foucault's view is that overt surveillance has been replaced by self-surveillance - we monitor and censor our thoughts and behaviour in discussion groups (Brookfield, 2005). Students in this study may never have known when they were being watched and their performance monitored and, therefore, constantly held themselves in subjection. As a result, they became afraid and self-conscious. This researcher would often notice students glancing at her to establish if they were being observed and to gauge her response to their contribution. They were constantly checking their behavior and were making a concerted effort not to falter. Many of them would self-correct (self-surveillance) after saying something even though this researcher saw no flaw in what they had said. On one occasion a student had delivered a good explanation of a particular learning issue, but concluded by saying: 'I have no idea what l've just said'. They became afraid of making mistakes because the risk of humiliation was too great. Students were in judgement of their own performance and proceeded to constrain themselves. 


\subsection{The directions in which surveillance works}

Foucault (1995) describes surveillance as working in different directions: top to bottom and bottom to top. In a PBL environment it is not only the student who is under surveillance, but the PBL tutor as well. As a PBL tutor, this researcher observed this to be the case as she felt herself being constantly watched to determine if she was implementing the procedures of PBL and to assess the manner in which she was interacting with the students.

During one particular PBL tutorial in the UK, this researcher offered an explanation from a particular theoretical position when it became evident that the students were struggling to understand a particular concept. In South Africa students would most likely have simply accepted the explanation. The UK students, however, researched what was said and, in the following session, indicated that the theory was outdated and promptly put forward a new theory. Thereafter, this researcher became vigilant about sharing knowledge and also held herself in subjection. Discussions with colleagues indicated that they had similar experiences with students, and were also hesitant to share their knowledge.

\subsection{Surveillance and self-surveillance as oppressive tools in constraining learning}

The continuous pressure of holding themselves in check could, in fact, have been stifling for the students who did not always feel free to explore or be spontaneous and this, arguably, could have hindered their creativity and problem-solving abilities. It has been extensively reported that PBL promotes generic skills and, in particular, encourages complex thinking skills such as creative, critical and analytical thinking (Boud and Feletti, 1997; Cohen-Schotanus, Muijtjens, Schönrock-Adema, Geertsma and van der Vleuten, 2008; Norman and Schmidt, 1992). When students are subjected to the PBL gaze, however, this becomes difficult to achieve. Owing to Panoptic principles, surveillance and self-surveillance in PBL group work could have been experienced as threatening and oppressive, and this could have had the potential to constrain learning. Therefore, even though the PBL environment was deemed to be learner-centered, it did not necessarily mean that students were not in a state of subjection.

What happened to students who were underperforming? In one instance, a student in this study had been humiliated by the PBL tutor because she was not an active member of the group. It later emerged that her mother was terminally ill and she found it difficult to concentrate on her work. She ultimately decided to drop out of the programme. PBL had become a threatening environment for her. Surveillance did not make concessions for her personal problems; it objectified her. Referring to the insidious effects of power, Tan cites that:

'It's object is to impose an ubiquitous pattern of normality and eliminate everything and everybody which does not conform. It may be seen that Problem-based Learning processes promote the observation, surveillance and examination of students which renders them knowable and identifiable as sites of intervention and control. Because disciplinary power requires knowledge of the subjects to be exercised efficiently, students who self-assess and demonstrate their competence (or lack of it) in Problem-based Learning invite and incite power to be exercised against them.'

\subsection{The multiplicity effect of the gaze}

Foucault explains that the Panopticon may even provide an apparatus for supervising its own mechanism. For instance, the director of an institution may spy on his employees and be able to judge them continuously and control their behavior. The director, in turn, can be under the gaze of an inspector who evaluates the functioning of the entire establishment. In this way, the effects of the gaze are multiplied.

The sharing of mutual support and criticism is vital to the success of PBL (Barrows and Tamblyn 1980); for this reason evaluation (self-, peer- and tutor-evaluation) is important in PBL (Hassan, 1996). In the UK, this researcher was the co-ordinator of the quality assurance of PBL and it was her responsibility to evaluate PBL tutorials. She did so by conducting peer- and student-evaluations of PBL tutor performance. It was this researcher's main role to ensure that PBL procedures were followed and that PBL tutors were managing group dynamics effectively. The PBL tutors were, therefore, under the surveillance of this researcher. In turn, this researcher was under the surveillance of the Director of the Centre. These layers of surveillance ensured and multiplied the effects of the power of the gaze, and its mechanism of operation was self-sustaining.

On one occasion, this researcher was asked by the Director of the Centre to undertake a peer-review on a PBL tutor because students had complained about her poor facilitation techniques. During the review of one of her tutorials, it became obvious that she was not providing much guidance and did not say much. The students, however, demonstrated their independence and took charge of the tutorial which was conducted effectively with all the PBL procedures being 
addressed. There was no need for the tutor to give continuous guidance and direct the students. After a certain period, the students had become self-directing, thereby achieving an important goal of PBL. There was, therefore, little to report on in terms of the tutor's performance as a tutor. Although she had not been an active facilitator, her presence ensured surveillance and self-surveillance, which led to the Panopticon's supervision of its own mechanism.

In South Africa, there were two PBL tutors per tutorial group. This researcher recalls the oppressive nature of this kind of 'team teaching'. Tutors struggled for power while being acutely aware of being held in subjection by the surveillance of the other tutor and the students. To a large extent, disagreements concerning the execution of the PBL process led to the heightened surveillance of one another.

\section{Conclusion}

This article argued from the perspective of Foucault's theories that the structured nature of group work in a PBL environment promotes the manifestation of power and dominance by some members to flourish, which creates an oppressive, threatening space where members are under constant surveillance. Although Foucault (1995) advises that surveillance has a function in moulding and developing a person, this article argues that the gaze can be construed as oppressive and can, in fact, stifle learning. The PBL gaze, therefore, has the potential to become oppressive.

As a result, the following recommendations are offered concerning ways in which to recognize the manifestation of power in the management of group dynamics so that group work can become a positive place for all group members:

- Students (especially those in the medical field) should be made aware of the power of surveillance. By alerting them to the notion of surveillance they will become aware of it in their future professional roles when surveillance and dominance manifests through medical tests on patients. Specifically, students will become cognizant of its potential oppressive power.

- Problem-based learning tutors need to be mindful of students being held in subjection, and the effect this could have on their learning.

- Surveillance objectifies students. PBL tutors must get to know their students on a personal level rather than simply observing their academic performance during group work.

- A forum for PBL tutors should be established to enable them to share their experiences of being, and feeling oppressed in a PBL environment.

The limitation of this study was that it did not situate the gaze with respect to gender, culture and class - as the experiences of oppression would not be diversity independent. This could be scope for future studies.

The intent in this article was to create awareness, stimulate dialogue, encourage critique and conscientize within an area that is often neglected during the pursuit of efficiency in the design and delivery of PBL. The endeavor here was to counter the blind acceptance of oppression in PBL contexts. PBL is often valorized as an alternative pedagogical approach to traditional methods of teaching and learning, and not enough is being documented about the problems with PBL. Much of what happens in the PBL environment goes uncontested. This is not to say that PBL should be discarded; rather, by identifying the deficiencies inherent in its application, strategies can be sought to optimize it as a more effective pedagogical tool. Furthermore, although this study has explored group dynamics within the context of PBL, the argument regarding group work not being power-free zones could extend to other forms of collaborative learning that involve group work.

\section{References}

Ball, S. J. (Ed.). (1990). Foucault and education: Disciplines and knowledge. London, Routledge.

Barrows, H.S., \& Tamblyn, L.M. (1980). Problem-based learning: An approach to medical education, vol. 1. New York: Springer.

Barrows, H.S. (1986). Taxonomy of problem-based learning methods. Medical Education,20, 481-486.

Baker, C. M. (2000). Problem-based learning for nursing: Integrating lessons from otherdisciplines with nursing experiences. Journal of Professional Nursing 16 (5), 258-266.

Brookfield, S. (2005). The power of critical theory for adult learning and teaching. Berkshire: Open University Press.

Boud, D, \& Feletti, G. (Eds.). (1997). The challenge of problem-based learning.(2nd ed.). London: Kogan Page.

Cohen-Schotanus, J., Muijtjens, A. M. M., Schönrock-Adema, J., Geertsma, J., andvan der Vleuten, C. P. M. (2008). Effects of conventional and problem-basedlearning on clinical and general competencies and career development. Medical Education, 42, 256-265.

Colliver, J. A. (2000). Effectiveness of problem-based learning curricula: Research and theory. Academic Medicine, 75(3), $259-266$.

Ertmer, P. A. \& Newby, T. J. (1993). Behaviourism, cognitivism, constructivism: Comparing critical features from an instructional design perspective. Performance Improvement Quarterly, 6, 50-72. 
De Grave, W.S., Boshuizen, H.P.A., \& Schmidt, H.G. (1996). Problem-based learning: cognitive and metacognitive processes during problem-analysis. Instructional Science, 24, 321-341.

De Grave, W. S., Dolmans, D. H. J. M., \& van der Vleuten, C. P. M. (1999). Profiles of effective tutors in problem-based learning: scaffolding student learning. Medical Education, 33, 901-906.

Drinian, J. (1997). The limits of Problem-based Learning. In D. Boud \& G. Felleti (Eds.), The Challenge of Problem-based Learning. London: Kogan Page.

Fenwick, T.J., \& Parsons, J. (1997). A critical investigation of the problems with problem-based learning. Research report: St. Francis University and University of Alberta. Retrieved Available: http://files.eric.ed.gov/fulltext/ED409272.pdf (October, 29, 2013).

Foucault, M. (1995). Discipline and punish: The birth of the prison. New York: Vintage Books. Translated from French by Alan Sheridan (c) 1977.

Grossen, M. (20080. Methods for studying collaborative creativity: An original and adventurous blend. Thinking skills and creativity, 3, 246-249.

Hassan, S. (1996). The perceptions of second year medical students towards the problem-based curriculum as compared to the traditional curriculum. Unpublished MEd. Thesis. Pretoria: University of South Africa (UNISA), South Africa.

Hassan, S. (2010) Developing staff for the implementation of problem-based learning: Experiences from Botswana. South African Journal of Higher Education, 24(1), 84-97.

Hassan, S. (2013, July). Group work in problem-based learning: Democratic spaces or oppressive places? Paper presented at the conference of the Higher Education Research and Development Society of Australasia (HERDSA) conference: 'The place of learning and teaching", Auckland University of Technology, New Zealand.

Hmelo-Silver, C.E. (2004). Problem-based learning: what and how do students learn? Educational Psychology Review, 16(3), 235-266.

Hmelo-Silver, C.E., \& Barrows, H.S. (2006). Goals and strategies of a problem-based learning facilitator. The Interdisciplinary Journal of Problem-based Learning, 1(1), 21-39.

Norman, G., \& Schmidt, H. (1992). The psychological basis of problem-based learning: A review of the evidence. Academic Medicine, 67(9), 557-565.

Papinczak, T., Tunny, T., \& Young, L. (2009). Conducting the symphony: a qualitative study of facilitation in problem-based learning tutorials. Medical Education, 43, 377-383.

Paulus, P.B. (Ed.). (1999). Group creativity: Innovation through collaboration. New York: Oxford University Press.

Reynolds, M., \& Trehan, K. (2000). Assessment: A critical perspective. Studies in Higher Education, 25(3), 267-278.

Schmidt, H.G., Cohen-Schotanus, J., \& Arends, L.R. (2009). The impact of problem-based, active learning on graduation rates for 10 generations of Dutch medical students. Medical Education, 43, 211-218.

Savery, J.R., \& Duffy, T.M. (1996). Problem Based learning: an instructional model and its Constructivist framework. In B.G. Wilson (Ed.), Constructivist learning environments: case studies in instructional design (pp. 135-148). Englewood Cliffs, N.J.: Educational Technology Publications.

Tan, K. Constrasting notions of power in problem-based learning. Learning academy. [Online] Available: http://tp.edu.sg/pbl_kelvin_tan.pdf (01/11/2013)

Van Berkel, H.J.M \& Dolmans, D.H.J.M (2006). The influence of tutoring competencies on problems, group functioning and student achievement in problem-based learning. Medical Education, 40, 730-736.

Walton, H. J. \& M. B. Matthews. (1989). Essentials of problem-based learning. Medical Education, 23, 542-558. 